\title{
1. Die russischen Deutschen und ihr Verhältnis zu Deutschland. Historischer Rückblick ${ }^{1}$
}

Im Vielvölkerstaat der Zaren stellten die Deutschen eine politisch mitbestimmende, wirtschaftlich potente und kulturell einflußreiche nationale Minderheit dar. Die starke sozio-ökonomische Stellung dieser Gruppe ergab sich - läßt man völkerpsychologische Gesichtspunkte zur Seite - unter anderem aus ihrer eigenartigen Zusammensetzung. Sie umfaßte die Deutschbalten - den Adel der Ritterschaften und das hanseatische Bürgertum -, die sich im Rahmen der deutschen Ostsiedlung seit dem 13. Jahrhundert ihren Platz auf slawischer Erde mit Schwert und Handel erkämpft hatten, ferner die deutschstämmige Bevölkerung der russischen Städte, die ihre Anfänge auf die Zeiten Iwan des Schrecklichen zurückführte, und schließlich die von Katharina der Großen ins Land gerufenen Bauern und bäuerlichen Handwerker, die Teile der südrussischen Steppengebiete urbar und fruchtbar gemacht hatten; ihre zusammenhängenden Siedlungskomplexe wurden verallgemeinernd und, wie sich später erweisen sollte, irreführend „Kolonien“ genannt ${ }^{2}$. Diese drei Bestandteile der deutschen Bevölkerung in Rußland hatten aufgrund ihrer unterschiedlichen Siedlungsgeschichte und Sozialstruktur bis zum Ende des 19. Jahrhunderts kaum das Bewußtsein, einer einheitlichen Volksgruppe anzugehören. Aus russischer Sicht allerdings besaßen alle nemcy ungeachtet ihrer verschiedenen Herkunft und sozialen Stellung die gleichen Charaktereigenschaften: diszipliniert und verläßlich, hart arbeitend, der Sache hingegeben, unbegrenzt einsatzfähig, das Gemeinwohl über das Eigenwohl stellend.

Wohl hatte es im 18. und 19. Jahrhundert, unter tätiger Förderung der russischen Krone, sporadische Verbindungen zwischen den einzelnen Bevölkerungsteilen gegeben. Deutschstämmige Mitglieder der Petersburger Akademie der Wissenschaften hatten die deutschen Siedlungskomplexe in Südrußland und im Wolgagebiet besucht und mit Faszination beschrieben; die staatliche Verwaltung der Ausländersiedlungen, der eine intakte innere Selbstverwaltung zur Seite stand, war nicht selten geadelten deutschen Stadtbewohnern oder Angehörigen des deutschbaltischen Adels aus den Reihen der bewährten russischen Bürokratie anvertraut; und die Universität Dorpat hatte über Generationen hinweg den Nachwuchs der protestantischen Pastorenschaft

\footnotetext{
${ }^{1}$ Anmerkungen und bibliographische Hinweise zu den beiden einleitenden Kapiteln sind aus Raumgründen auf ein Minimum beschränkt. Eine breite Präsentation des Stoffes bis Ende des Ersten Weltkrieges ist in Vorbereitung.

${ }^{2}$ Eine den heutigen Ansprüchen genügende Gesamtdarstellung liegt noch nicht vor. Aus der älteren Literatur vgl. Dukmeyer, F., Die Deutschen in Rußland, München 1916. Zum Stand von Literatur und Forschung: Schiller, F.P., Literatur zur Geschichte und Volkskunde der deutschen Kolonien in der Sowjet-Union für die Jahre 1764-1926, Pokrowsk 1927; Long, J.W., The German Russians. A Bibliography of Russian Materials, Sa. Barbara/Ca. 1979; Stumpp, K., Das Schriftum über das Deutschtum in Rußland, Stuttgart 1980.
} 
und zum Teil der Lehrerschaft der deutschen Siedlungsgebiete gestellt. Doch hatten diese geringen Berührungsflächen niemals ein Gemeinschaftsbewußtsein entstehen lassen. Zu stark wich die politisch-soziale Orientierung der drei Einzelgruppen voneinander ab:

Der weithin konservative Baltenadel verstand sich seit der Zeit Peters des Großen als Stütze der Autokratie. Seine starke Stellung im Militär- und Zivildienst, in der Diplomatie, im Geheimdienst des russischen Reiches, dazu in Wissenschaft und Forschung hatte ihm für Jahrhunderte ein Eigengewicht verliehen, das jede nationale Orientierung überflüssig erscheinen ließ.

Die deutsche Stadtbevölkerung - liberale und akademische Intelligenz, aber auch das in Gilden organisierte Handwerk sowie das sich ab Anfang des 19. Jahrhunderts entwickelnde Industriellen- und Großbürgertum - war, durch entsprechende Fremdengesetzgebung gefördert, zu einer sich stark assimilierenden Kraft geworden. Ihr unternehmerischer Elan, der sie bald bis in die entlegensten Teile des russischen Reiches führte, und ihre in die höheren und höchsten Gesellschaftsschichten drängende soziale Mobilität (Aufstieg in den Adelsstand und Ehrenbürgerwürden) machten sich gerade bei weitgehender Integration in die russische Gesellschaft und Sozialstruktur vollbezahlt.

Die deutschen Siedler, seit ihrer Einbürgerung unter Zarin Katherina II. offiziell Kolonisten genannt, stellten mit ihren geschlossenen Wohngebieten, ihrer wohlausgebildeten inneren Selbstverwaltung (1764-1871) und ihrer sprachlich-kulturellen Isoliertheit in der Tat eine Art „Staat im Staate" dar. Hier konzentrierte sich das Hauptinteresse der Bevölkerung auf Ackerbau und Viehzucht, eine auf Binnengruppen orientierte religiöse Lebensführung (so bei den Mennoniten und Pietisten) und - bei gleichzeitiger sozio-ökonomischer Expansion - auf die Tradierung hergebrachter Kulturformen.

So unterschiedlich diese Gruppen in ihrer spezifischen Orientierung waren, unter zwei Aspekten bestand Einheitlichkeit: Ihre Bindung an Rußland war neben dem wirtschaftlichen Interesse durch eine uneingeschränkte Loyalität zur russischen Krone bestimmt; das Vertrauen in den Monarchen half besonders Kolonisten und Baltenadel auch in Zeiten der Krise, Spannungen und Reibungen mit Teilen der örtlichen Bevölkerung oder mit der russischen Verwaltung zu überwinden. Zu ihrem Herkunftsland dagegen - den deutschen Kleinstaaten bzw. ab 1871 dem neuen Deutschen Reich - hatten sie weithin ein gebrochenes Verhältnis. Die deutschbaltischen Adeligen, die sich in historisch entscheidenden Auseinandersetzungen von den deutschen Fürsten allein gelassen, ja verraten gefühlt hatten, waren Peter dem Großen mit Respekt und Vertrauen entgegengekommen, um aus seiner Hand die Privilegien zu empfangen oder bestätigt zu erhalten, die einen geordneten und für seine und ihre Interessen förderlichen Lauf der Dinge erlaubten. Anders als das in Kleinstaaten zerstückelte Deutschland bot ihnen das zentralistische Riesenreich der Zaren, die wohlfundierte Landesautonomie und Ständeordnung der russischen Ostseeprovinzen und ihre auf immensen Ländereien basierende wirtschaftliche Unabhängigkeit jenen agrarisch-feudalen Status, der in Deutschland, zumal im 19. Jahrhundert, bereits zu 
schwinden begann. Die Revolution von 1848 und der mit ihr in Deutschland einsetzende demokratisch-liberale Geist vertieften diese Kluft. Und wenn auch bei der Gründung des neuen Deutschen Reiches bei geringen Teilen des durch den Anbruch der Reformzeit in Rußland verunsicherten deutschrussischen Landadels Hoffnungen auf eine stärkere Rückbindung an ein geeinigtes Deutschland aufgekommen sein mochten, so waren diese doch nur kurzlebig - die Rußland-Politik Bismarcks folgte gerade in Hinblick auf die russischen und speziell baltischen Deutschen den Prinzipien strengster Nichteinmischung. Die nationalen und nationalistischen Kreise, die eine Rückendeckung durch das erstarkende deutsche Reich nicht ungern erfahren hätten, waren damit auf die eigenen Kräfte zurückverwiesen.

Die deutschen Kolonisten hatten sich in der Regel bei ihrer Einwanderung ins Zarenreich im wahrsten Sinne des Wortes von ihrer Heimat abgewandt. Außer Verwüstung und Zerstörung (wie im Siebenjährigen Krieg) oder religiöser Intoleranz und Verfolgung (wie im Falle der Mennoniten und anderer Sektierer) waren es vor allem die durch das deutsche System der Erbteilung bedingte Bodenzerstückelung und das daraus resultierende Hungerleben, die sie aus dem Land getrieben hatten. Für sie bedeutete Rußland in erster Linie Land (im Durchschnitt 60 ha pro Familie) und Freiheit, das hieß: freie Entfaltung ihrer seit langem verkümmernden Kräfte. Nach Deutschland schauten sie kaum, wenn nicht sogar mit schlechten Erinnerungen zurück. Eine Rückwanderung in die deutschen Fürstentümer, so leicht und selbst profitabel eine solche nach dem russischen Sonderrecht für den Kolonistenstand auch hätte sein können, fand kaum statt. Und wenn Kolonisten in außergewöhnlichen Situationen, wie etwa in den Hungerjahren an der Wolga (frühe 1880er und 1890er Jahre) oder bei der Einführung der allgemeinen Militärdienstpflicht - hier waren es nicht kämpfende Mennoniten - Rußland verließen, so gingen sie nicht nach Deutschland, sondern nach Nord- und Südamerika oder Kanada.

Die deutschstämmige Bevölkerung der russischen Städte, der assimilationsfreudigste Teil der Deutschrussen, lockerte in der Regel bereits in der ersten Generation in Rußland die etwa noch zum Herkunftsland bestehenden Bande. In der zweiten oder dritten Generation, in der meist auch der Übergang in den russischen Untertanenverband vollzogen wurde, war neben dem deutschklingenden Namen, der nicht-orthodoxen Konfession und einer Art weltbürgerlich-deutschen Kulturbewußtseins selten noch ein reales Verhältnis zu Deutschland vorhanden. Auch die deutsche Reichsgründung unter Bismarck löste keinen entscheidenden Wandel aus. Im Gegenteil, gerade in dieser Zeit zog das sich eben modernisierende Zarenreich neue unternehmerische deutsche Kräfte en masse ins Land. Ihr durch die freizügige Ausländergesetzgebung Alexanders II. erleichterter Einstieg in Handel und Industrie sowie der allgemeine Wirtschaftsaufschwung der russischen Gründerjahre, von dem sie in hohem Maße profitierten, begünstigten ihre Verschmelzung mit der russischen Gesellschaft. Nicht selten kam es bei deutschstämmigen Elementen in den russischen Großstädten, allen voran in Petersburg, Moskau und Odessa, zu einer „Überanpassung “ an die russische Sprache, Literatur und Wissenschaft, vergleichbar etwa dem Verhalten deutschjüdischer Intelligenz im Preußen der Judenemanzipation. 
Gegen Ende des 19. Jahrhunderts war die deutsche Bevölkerung mit 1,31\% der Gesamtbevölkerung auch demographisch ein gewichtiger Faktor des Russischen Reiches geworden. Die erste gesamtrussische Volkszählung ${ }^{3}$ ergab, daß etwa 1,8 Millionen Deutsche im Zarenreich lebten (1790489 russische Untertanen deutscher Sprache und Herkunft, 1813717 Personen deutscher bzw. ihr benachbarter Sprachzugehörigkeit). Von diesen lebten 1312188 deutschstämmige Untertanen (bzw. 1333663 deutschsprachige Personen) in den fünfzig Gouvernements des europäischen Rußland, 407274 (407 780) im russischen Polen, 56729 (57 502) im Kaukasusgebiet, 5424 (5825) in Sibirien und 8874 (8947) in Mittelasien. Der sozialen Gruppierung nach gehörten ca. 1,3 Millionen (oder rd. 77\%) der Deutschen in Rußland der Landbevölkerung und 401960 Personen (23\%) der Stadtbevölkerung an. Nach Ständen und Berufsgruppen aufgeschlüsselt, waren 1033282 deutsche Untertanen des Zaren (57,7\%) in der Land- und Forstwirtschaft und 375953 (21\%) in der Industrie tätig. 112453 (6,3\%) waren Arbeiter und Bedienstete. 97796 (5,5\%) nahmen Positionen in Handel und Verkehr ein. 11768 (0,6\%) waren Kaufleute. Ca. 50000 Deutsche gehörten akademischen Berufen und eine ebenso große Zahl dem Adel (24854 oder 1,4\% dem Erbadel, 17134 oder weniger als 1\% dem persönlichen Adel) und dem Stand der Ehrenbürger an.

In den knapp zwei Jahrzehnten bis zum Ausbruch des Ersten Weltkriegs setzte sich die außergewöhnliche sozio-ökonomische Expansion der deutschen Bevölkerung, die besonders seit den 1880er Jahren zu beobachten gewesen war, fort. Im Jahre $1914^{4}$ lebten im Zarenreich 2443575 Deutsche. Die zahlenmäßig größte Gruppe wohnte im Wolgagebiet (619670). Ihr folgten die Deutschen des Schwarzmeergebietes (der russischen Gouvernements Jekaterinoslaw, Cherson und Taurien mit Bessarabien: 600000), Kongreßpolens (500000), Wohlhyniens (210000), der baltischen Provinzen (165000), Sibiriens (75830), von Petersburg-Stadt (50000) und -Land (10680), des Nord- (49000) und Südkaukasus (17000), des Dongebietes (46000) und der Gouvernements Wilna, Kowno und Grodno (40000). Des weiteren lebten etwa 18000 Deutsche im Gouvernement Kiew, 4000 in Podolien, 5475 im Gebiet von Orenburg, 6650 im Gebiet von Ufa und 25270 in den innerrussischen Gouvernements Woronesch und Tschernigow sowie in vereinzelten Siedlungen über das ganze Reich hin.

Die Deutschen Rußlands verfügten über einen legendären Landbesitz, der mit ca. 14 Millionen ha bei Ausbruch des Ersten Weltkrieges (das waren ca. $43 \%$ der landwirtschaftlichen Nutzfläche des damaligen Deutschland) wohl nicht zu hoch veranschlagt worden ist. Um das Jahr $1910^{5}$ registrierte man an deutschbaltischem Grundbesitz 4 Millionen Desjatinen ( 1 Desj.=1,09 ha), in den süd- oder neurussischen

\footnotetext{
${ }^{3}$ Rossija. Central'nyj Statističeskij Komitet. Dépouillement des Donnés sur la Nationalité et Classification des Peuples de l'Empire Russe d'après leur Langue, St. Petersburg 1899; Relevé Général pour tout l'Empire de Russie des resultats du dépouillement des donnés du premier recensement de la population en 1897, St. Petersburg 1905.

${ }_{4}$ Mergenthaler, A., Das Rußlanddeutschtum in Zahlen, Leipzig 1939.

${ }^{5}$ Schmidt, E., Die deutschen Bauern in Südrußland, Berlin $1917^{2}$.
} 
Gouvernements mit Bessarabien waren weit über 4 Millionen Desj. in deutschem Besitz, im Wolgagebiet (Gouvernements Saratow und Samara) 2 Millionen Desj., im polnisch-wolhynischen Gebiet 1 Million Desj., in Sibirien und Mittelasien 750000 Desj. und im Petersburger und den innerrussischen Gouvernements 450000 Desj.

Die außergewöhnliche sozio-ökonomische Vitalität und Grundbesitzexpansion der Deutschstämmigen waren seit Mitte der 1880er Jahre - nicht zuletzt unter dem Eindruck der massiven deutschen Siedlungsbewegungen von Polen nach Wolhynien für den panslawistischen Flügel der russischen Presse zum Omen eines politisch motivierten und von Berlin gesteuerten, neuerlichen deutschen „Drangs nach Osten“ geworden. In der Tat wandte im deutschen Kaiserreich die Kolonial- und die aus ihr hervorgehende alldeutsche Bewegung dem Landbesitz deutscher Siedler und Adeliger in Rußland ihr wachsendes Interesse zu - in zunehmendem Gegensatz allerdings zu den von Bismarck gelegten Grundlagen einer besonnenen Ostpolitik. 